\title{
ELEMENTOS DE JOGOS EDUCACIONAIS DIGITAIS PARA EDUCAÇÃO INFANTIL
}

\section{Daiani Marques Gonçalves'; Gabriel Rodrigues Felipetto²; Toni Pereira Dorneles $^{3}$; Viviane Arruda Machado Leal ${ }^{4}$; Ana Marli Bulegon ${ }^{5}$}

\section{RESUMO}

Este trabalho tem por objetivo apresentar alguns elementos que um jogo educacional digital deve apresentar para ser utilizado com crianças na Educação Infantil. Durante o ano de 2021, de forma remota, foram realizadas reuniões quinzenais de pesquisa, estudos e discussões acerca da Educação infantil e tipos de jogos para esse nível de ensino. Participaram dessas reuniões acadêmicos do curso de Jogos Digitais (UFN), mestranda e docente do Programa de Pós-Graduação em Ensino de Ciências e Matemática (PPGECIMAT-UFN). Os resultados apontam como elementos que os jogos digitais devem apresentar para serem utilizados na Educação Infantil como: um game design intuitivo; conter poucas mecânicas e elas devem ser de fácil manuseio; temáticas e personagens relacionadas ao mundo infantil; os aspectos visuais devem conter cores vibrantes; o áudio conter narração, sons e músicas descontraídas; outros.

Palavras-chave: Cultura Digital, game design, interface amigável, linguagem digital, letramento digital.

\section{INTRODUÇÃO}

O ensino remoto, em muitos casos on-line, foi implementado em resposta à pandemia de COVID-19 na maioria das escolas brasileiras para todos os níveis escolares. Isso representou um grande desafio para os professores que precisaram repensar suas atividades e fornecer instruções on-line envolventes. Na Educação Infantil, os documentos oficiais da Educação brasileira apontam que esse nível de ensino é considerado a primeira etapa da Educação Básica e, de acordo com a Lei no

\footnotetext{
1 Acadêmica do curso de Jogos Digitais (UFN); Bolsista UFN

2 Acadêmico do curso de Jogos Digitais (UFN)

3 Acadêmico do curso de Jogos Digitais (UFN)

4 Pedagoga e Mestranda do Programa de Pós-Graduação em Ensino de Ciências e Matemática (PPGECIMAT-

UFN)-vivianeleal258@gmail.com

5 Doutora e Docente do Programa de Pós-Graduação em Ensino de Ciências e Matemática (PPGECIMAT-UFN) - anabulegon@ufn.edu.br
} 
9.394/1996 (Lei De Diretrizes e Bases da Educação Nacional - LDB), tem como finalidade o desenvolvimento integral da criança de até 5 anos e 11 meses de idade "em seus aspectos físico, psicológico, intelectual e social, complementando a ação da família e da comunidade" (BRASIL, 1996, art. 29). Portanto, esse nível de ensino necessita promover o desenvolvimento da criança em todos os seus aspectos, de forma integral, constituindo-se alicerce para o pleno desenvolvimento infantil.

Por outro lado, o público desse nível de ensino já nasceu imerso no mundo das tecnologias digitais de informação e comunicação (TDIC) e necessita, cada vez mais, desenvolver habilidades e competências do uso delas a fim de fomentar o desenvolvimento de sua Cultura Digital, como proposto pela Base Nacional Comum Curricular (BNCC), para a Educação Brasileira.

No âmbito da Educação, as TDIC pouco eram utilizadas na Educação Infantil, mas com o ensino remoto on-line surgiu a necessidade de usar recursos delas. Dentre tantas opções, uma delas foi o uso de jogos educacionais digitais. Nesse sentido, o Grupo de Estudos e Pesquisas em Tecnologias de Informação e Comunicação (GEPTIC), vinculado ao Programa de Pós-Graduação em ensino de Ciências e Matemática (PPGECIMAT-UFN), interessados no desenvolvimento de Jogos Educacionais Digitais, buscou respostas para o seguinte questionamento: Quais são os elementos que um jogo educacional digital deve apresentar para ser utilizado com crianças da Educação Infantil? Para responder esse questionamento, este trabalho relata os resultados das pesquisas, estudos e discussões desse grupo.

\section{METODOLOGIA}

Trata-se de uma pesquisa bibliográfica, com abordagem qualitativa, do tipo exploratória e descritiva, realizada em livros e artigos científicos, presentes nas bases

de dados do Google Acadêmico e Scielo. Foi desenvolvida em 2021, por um grupo de acadêmicos do curso de Jogos Digitais (Bolsistas PIBIC e PIBITI-UFN) e por uma mestranda e uma docente do Programa de Pós-Graduação em Ensino de Ciências e Matemática (PPGECIMAT-UFN), integrantes do GEPTIC. Os resultados dessa pesquisa foram discutidos e sintetizados pelos participantes do GEPTIC e darão base 
para a criação de um jogo educacional digital (Produto Educacional da mestranda) para ensinar o conceito de Números e quantidades, para a Educação Infantil.

\section{MARCO TEÓRICO}

$\mathrm{Na}$ sociedade contemporânea, ao sair às ruas, é notável a quantidade de pessoas que utilizam seus celulares, seja de maneira convencional, como em um telefonema, ou escrevendo mensagens de texto via internet. Acessar a web para escrever ou trocar mensagens, enviar e receber e-mails, visitar sites ou mesmo postar uma selfie nas redes sociais são ações que já se tornaram algumas das principais funções desses aparelhos.

Dada a praticidade e facilidade que as tecnologias móveis oferecem aos usuários, quanto a navegação e interação, elas estão adquirindo um número cada vez maior de usuários e já fazem parte do cotidiano dos estudantes (CAON e SANTOS, 2015). Com isso, torna-se imprescindível preparar os estudantes para lidar com a proliferação e explosão das informações e outras rápidas mudanças tecnológicas e para adaptar-se aos diferentes campos profissionais. Além disso,

[...] a escola do novo milênio deve preparar os estudantes para a cidadania digital e para a autoria. A tecnologia é uma linguagem a ser dominada para que o aprendiz possa criar, não apenas curtir e compartilhar conteúdo. A ênfase não está nas ferramentas digitais em si, mas nas possibilidades de interação, produção, solução de problemas e colaboração que a tecnologia proporciona (SASSAKI, 2017, p.7).

Diante dessa demanda os cenários educacionais têm de ser repensados e os modelos de ensino discutidos para incorporar os processos de autoria dos estudantes na construção do conhecimento, que não é somente deles, mas também de professores e de toda comunidade escolar. O novo modelo de ensino deve valorizar as competências e

[...] as habilidades, consideradas relevantes não apenas para o sucesso acadêmico, como para as jornadas profissional e pessoal dos indivíduos. Elas se dividem entre habilidades cognitivas (como memória, análise, pensamento crítico, argumentação), interpessoais (como liderança, cooperação, resolução de conflitos, empatia) e intrapessoais (como ética, resiliência, curiosidade, autoconhecimento) (SASSAKI, 2017, p.7). 
De acordo com a BNCC, uma das competências que os estudantes devem ter desenvolvido ao final da Educação Básica é a Cultura Digital, de modo que eles "Compreendam, utilizem e criem tecnologias digitais de forma crítica, significativa e ética."(BRASIL, 2016, p.31) a fim de que os estudantes possam "comunicar-se, acessar e produzir informações e conhecimentos, resolver problemas e exercer o protagonismo e a autoria."(BRASIL, 2016, p.31). Para o desenvolvimento da Cultura digital a BNCC aponta algumas dimensões que compreendem não apenas o uso crítico das tecnologias digitais, mas também a produção multimídia com conhecimentos de linguagens de programação e uso ético das tecnologias, mídias e dispositivos digitais. Além disso, prevêem que os sujeitos que tenham desenvolvido a cultura digital saibam compreender o impacto das tecnologias na vida das pessoas e na sociedade.

\section{EDUCAÇÃO INFANTIL}

A Educação Infantil, primeira etapa da Educação Básica, tem o objetivo de desenvolver integralmente a criança nos aspectos integrais: físicos, intelectuais, psicológicos e sociais, complementando as ações da família e comunidade. A escola, para auxiliar no desenvolvimento infantil, em todas essas perspectivas, precisa propor diversas experiências e espaços de aprendizagem, inclusive aquelas com as TDIC. Para isso o ambiente escolar deve ser rico em estratégias que valorizem os conhecimentos prévios dos estudantes, contribuindo para o seu desenvolvimento integral.

Os participantes da Educação Infantil são crianças de até 5 anos e 11 meses. São chamadas de nativos digitais porque já nasceram imersas no mundo tecnológico e tem suas relações baseadas nelas. De acordo com Prensky (2001, p. 2) "Eles passaram a vida inteira cercados e usando computadores, videogames, tocadores de música digitais, câmeras de vídeo, telefones celulares, e todos os outros brinquedos e ferramentas da era digital." Por conta disso, "Nossos estudantes de hoje são todos "falantes nativos" da linguagem digital dos computadores, vídeo games e internet." (PRENSKY, 2001, p.1). Essa linguagem é baseada em imagens e sons. Além disso, 
Os Nativos Digitais estão acostumados a receber informações muito rapidamente. Eles gostam de processar mais de uma coisa por vez e realizar múltiplas tarefas. Eles preferem os seus gráficos antes do texto ao invés do oposto. Eles preferem acesso aleatório (como hipertexto). Eles trabalham melhor quando ligados a uma rede de contatos. Eles têm sucesso com gratificações instantâneas e recompensas frequentes. Eles preferem jogos a trabalhar "sério". (PRENSKY, 2001, p.2)

Nesse sentido, ao focarmos no desenvolvimento da Cultura Digital em crianças, pensamos em aulas interativas e audiovisuais, com administração do tempo e do espaço de uso das TDIC. É importante que os recursos utilizados no ensino estimulem a autonomia, a criatividade e o protagonismo dos estudantes, a fim de fomentar neles o desenvolvimento de habilidades e competências, inerentes ao mundo moderno e a Cultura Digital.

Assim, os recursos tecnológicos utilizados na Educação infantil devem conter elementos que contemplem a linguagem digital. Dando ênfase na utilização de ferramentas tecnológicas com intencionalidade educativa, que estimulam vivências que facilitam a internalização do conhecimento.

Hoje é consenso que as novas tecnologias de informação e comunicação podem potencializar a mudança do processo de ensino e de aprendizagem e que, os resultados promissores em termos de avanços educacionais relacionam-se diretamente com a ideia do uso da tecnologia a serviço da emancipação humana, do desenvolvimento da criatividade, da autocrítica, da autonomia e da liberdade responsável. (ALMEIDA; PRADO, 1999, p.1)

Diante dessa perspectiva o educador precisa compreender que crianças pequenas chegam à escola trazendo conhecimentos, vivências que devem ser ponto de partida para a construção e ampliação da aprendizagem.

As tecnologias aliadas às propostas curriculares da Educação Infantil permitirão às crianças explorar novas vivências aprendendo pesquisar, questionar, expressar sua opinião, pensar e elaborar ideias de maneira lúdica, interativa e divertida, tornando o processo de aprendizagem mais interessante e significativo.

\section{JOGOS EDUCACIONAIS DIGITAIS}

Os jogos sempre foram atividades atrativas para o ser humano e fazem parte do arcabouço de recursos e estratégias utilizados na Educação Infantil. De acordo 
com Dorneles, Torres e Bulegon (2019) “Jogar é uma atividade que mantém a mente em constante movimento; desenvolve diversas habilidades, desde a lógicomatemática, motoras, etc. até a espacial." Com a chegada dos videogames, a popularidade dos jogos aumentou ainda mais e "As crianças, na atualidade, imersas no contexto tecnológico, veem os jogos digitais como seu meio de entretenimento." (DORNELES, TORRES, BULEGON, 2019, p.3), pois eles possuem elementos (mecânicas, desafios, regras, etc.) que proporcionam um ambiente lúdico e permite que o jogador brinque como se fizesse parte do jogo. Além disso, as tecnologias móveis permitem que eles sejam acessíveis em qualquer tempo e espaço. De acordo com Mattar (2010),

O uso de jogos digitais como ferramenta educacional, respeitam os diferentes estilos de aprendizagem e com isso permitem uma maior aproximação entre conteúdo e alunos, principalmente por poder atender às principais características de aprendizagem dos nativos digitais, além de fazer parte do seu dia a dia e do seu mundo (p. 5).

Para Gabriel (2013, p.219), "Os jogos sempre foram um instrumento poderoso para a educação, pois sua estrutura envolve objetivos e metas que, para serem atingidos, requerem a superação de obstáculos." Para De Aguileira (2003) o uso de jogos no ensino mostra-se uma estratégia vantajosa porque eles apresentam as informações em pequenas quantidades e favorecem a metacognição. Além disso, eles podem ser utilizados em qualquer tempo e espaço, permitindo que seus usuários pensem e avaliem sobre seus acertos e erros, o que permite o desenvolvimento da aprendizagem significativa.

De acordo com Beza (2011, p.3), "a indústria de jogos transformou-se em um dos mercados mais bem-sucedidos e lucrativos." Entretanto, KlopFer, Osterweil e Salen (2009) reforçam que há uma necessidade de avançar no campo da produção de jogos educacionais, pois atualmente são poucos os modelos para guiar o desenvolvimento desses jogos e os existentes não contemplam de modo eficaz a criação de jogos para todos os níveis escolares..

\section{RESULTADOS E DISCUSSÕES}


Nossas pesquisas apontam que o processo de desenvolvimento de um jogo digital inclui atividades essenciais do game design, como: elaboração de mecânicas, regras, narrativa, eventos, imagens, rankeamento, estética, sons e sensações que o jogador irá prestigiar, entre outros. Esses elementos garantem diferentes emoções e sentimentos, o que proporciona aos jogadores de todas as idades o engajamento, a interação e a imersão do jogador. No ponto de vista do aprendizado a estratégia pedagógica com uso de jogos é centrada nos estudantes; os aspectos lúdicos geram diversão ao jogador e contribuem, sobremaneira, para a aprendizagem.

Uma das teorias utilizadas nos jogos digitais para causar esses resultados é a Teoria do Flow, criada e desenvolvida pelo psicólogo Mihaly Csikszentmihalyi (2014), ela fala sobre o estado mental de felicidade e envolvimento ao fazer uma atividade (Figura 1).

Figura 1: Teoria do Flow

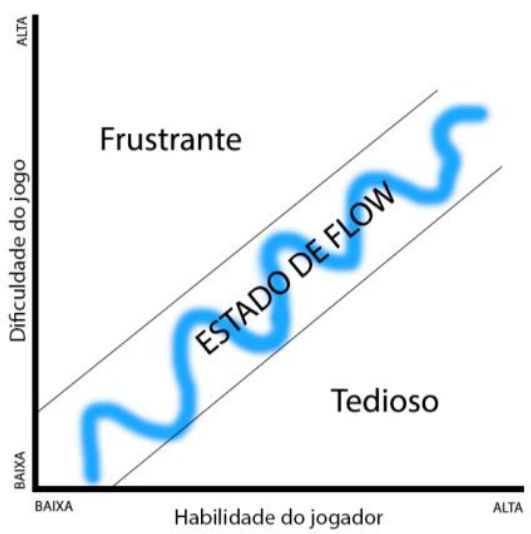

Fonte: Adaptado de Csikszentmihalyi (2014)

De acordo com essa teoria, o ideal é o equilíbrio entre os desafios propostos e as habilidades requeridas para jogar. Se o jogo oferece muitos desafios e dificuldades o jogador tende a se frustrar, na medida que não consegue superá-los, e desiste de jogar. Ao mesmo tempo, se altas habilidades são requeridas no jogo, há uma tendência a desistir de jogar, pois pode tornar-se entediante. Nesse sentido, é preciso combinar o tipo de desafio e de habilidades requeridas no jogo para cada faixa etária.

No caso dos jogos para crianças, àquelas que têm idade entre 4 e 5 anos, mostra-se mais apropriado utilizar um conjunto de mecânicas (ações que o jogador 
tem que executar) com poucos elementos simultâneos (como objetos coloridos, interface amigável, sons, imagens e personagens que representem a vida cotidiana, funcionalidades, objetivos, variáveis, formas de comportamento, etc.), pois a criança está em uma fase de aprendizado básico sobre como os elementos da vida funcionam. Esses aspectos proporcionam desafios suaves, em nível crescente e divertido. Colocar um alto número de elementos em uma fase do jogo tornaria a experiência muito demandante para a criança, com vários elementos novos para assimilar e interagir de uma só vez, o que pode deixá-la frustrada.

Em um jogo de argolas (Figura 2), por exemplo, há mecânicas de movimentação e arremesso das argolas enquanto uma garrafa de água se movimenta lentamente para os lados. O jogador deve acertar o maior número de argolas possível na garrafa, de acordo com o número de argolas que ele tem disponível (quantia determinada por um dado que é rolado no começo do jogo). A mecânica utilizada nesse jogo oferece uma crescente dificuldade à medida que o jogador adquire experiência com o jogo, favorecendo o estado de Flow.

Figura 2 - Interface do Jogo das Argolas

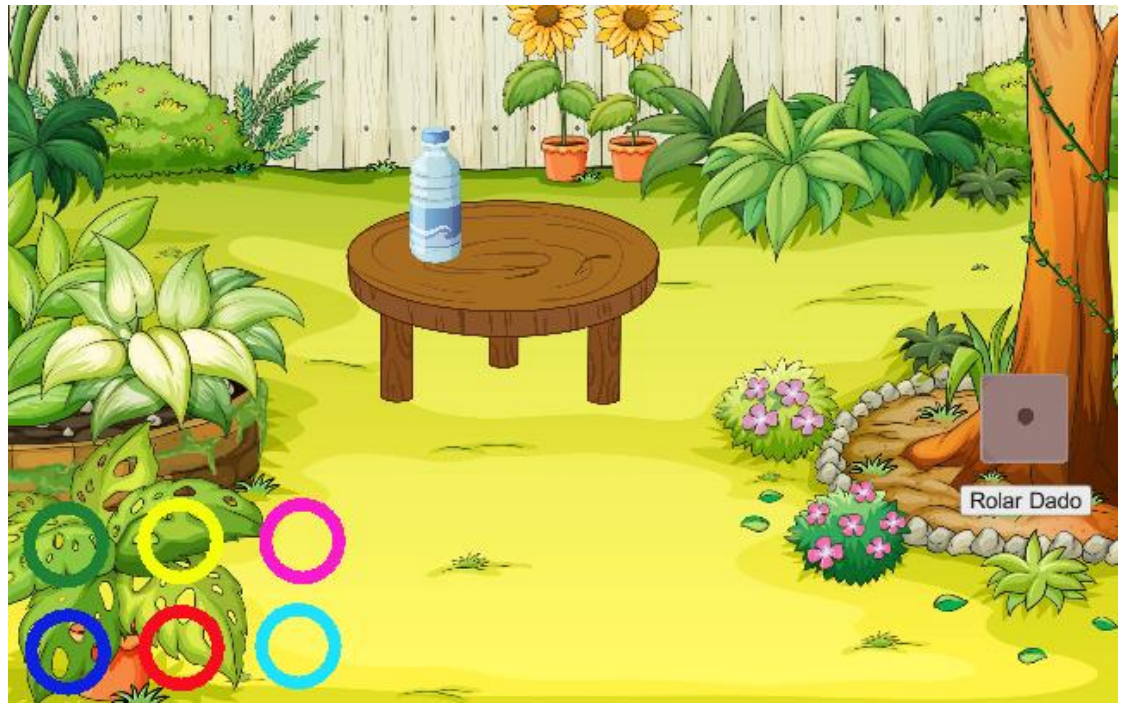

Fonte: os autores

As cores e gráficos, que compõem a estética da interface, são importantes para desenvolver um jogo educacional digital para Educação Infantil, da mesma forma que 
um desenho tem o poder de prender a atenção de uma criança para assisti-lo. Os jogos com cores vibrantes, por exemplo, cativarão mais as crianças do que aqueles com cores sóbrias.

Para o jogo trazer mais engajamento e favorecer sua rejogabilidade ele conta com a mecânica de rankeamento (Figura 3). Essa mecânica é abordada de forma sutil e divertida em jogos infantis a fim de motivar as crianças a jogar novamente.

Figura 3 : Exemplo de Rankeamento

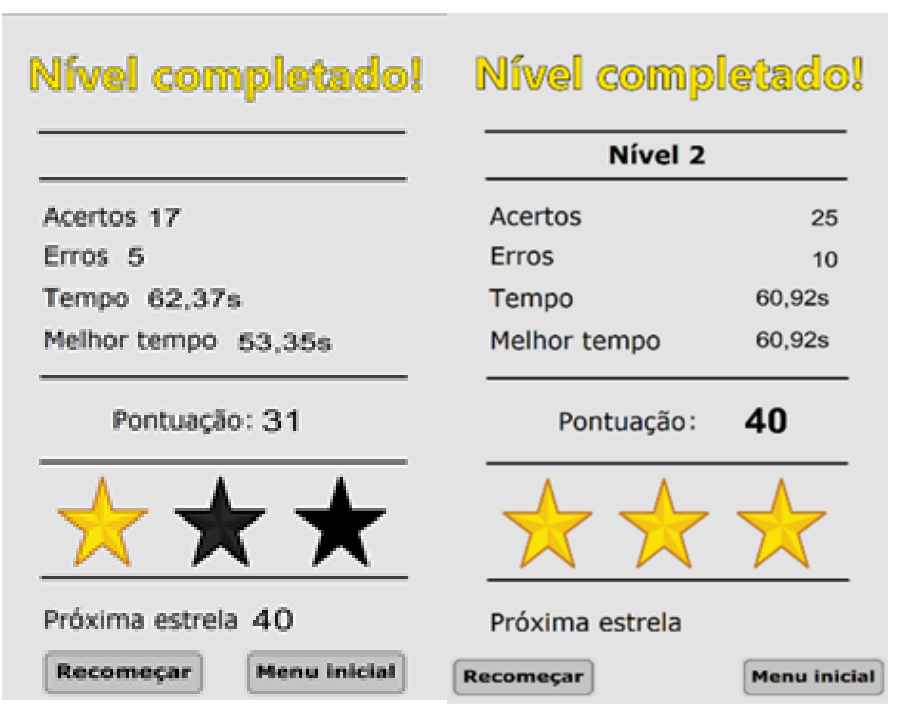

Fonte: os autores

Além dessa mecânica encontramos muitos efeitos sonoros divertidos e alguns jogos possuem também narração. Os efeitos sonoros proporcionam ao jogador diversas emoções e maior imersão no jogo, pois dão sentido ao contexto e interface; fornecem o feedback sobre os resultados das jogadas, entre outros. Sons de narração faz com que os jogos se tornem mais intuitivos para as crianças; estimulando-as a desbravarem aquele mundo sozinhas. As narrações, produzidas por personagens, instrutores ou avatares (Figura 4), despertam a sensação de afetividade e promovem a interatividade do jogador com o jogo. 
Figura 4 - Exemplo de uso de Avatar

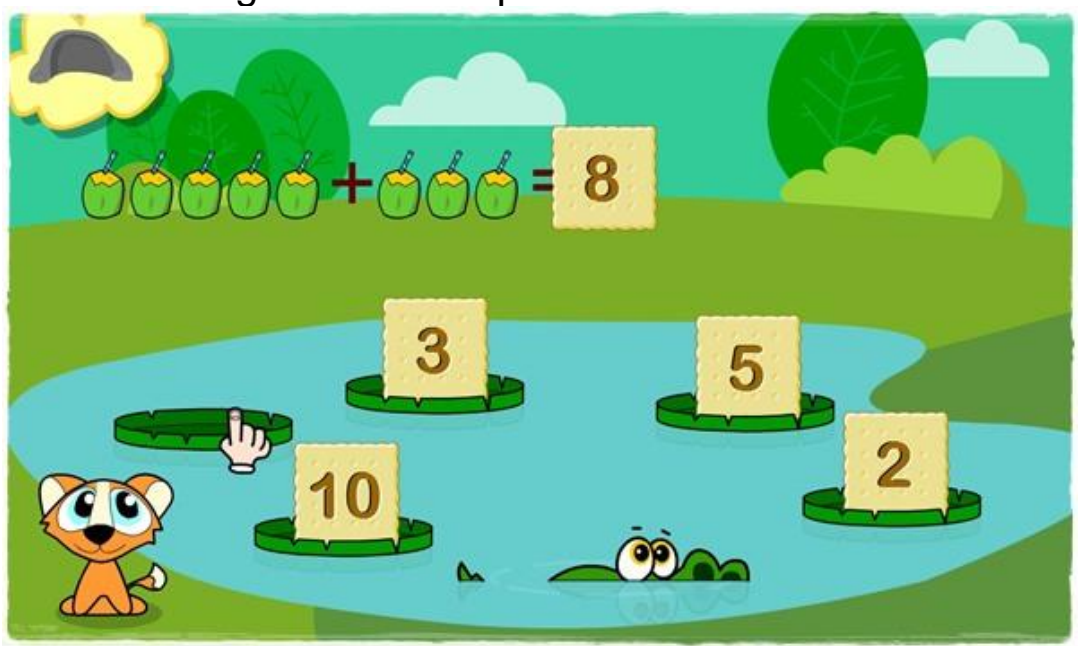

Fonte: Tela do jogo Brincando com Ariê

As histórias que compõem as narrativas precisam ser adequadas a faixa etária de seus usuários, pois despertam a atenção, sentimentos e emoções, desenvolvendo o desejo de continuar a jogar.

\section{CONSIDERAÇÕES FINAIS}

Produzir jogos educacionais digitais requer o conhecimento sobre os elementos técnicos e não técnicos, a fim de saber os gostos do jogador e proporcionar neles sentimentos e emoções capazes de manter-se ativos nos jogos e produzir o engajamento e a aprendizagem por meio deles.

Neste trabalho buscamos compreender quais são os elementos não técnicos que um jogo educacional digital deve apresentar para ser utilizado com crianças na Educação Infantil. Os resultados apontam para: um game design intuitivo; conter poucas mecânicas e elas devem ser de fácil manuseio; temáticas relacionadas ao mundo infantil; os aspectos visuais devem conter cores vibrantes; o áudio conter narração, sons e músicas descontraídas; os personagens contarem com avatares e animais; outros.

Já os elementos técnicos, envolvem a prática com softwares e habilidades capazes de manuseá-los, a fim de produzir um produto de maneira rápida e com baixo custo sem a perda de qualidade. Junto com a prática de softwares, encontra-se o conhecimento deles; através disso é possível produzir produtos reutilizando 
componentes, como: objetos, imagens, códigos, interface, entre outros, agilizando ainda mais o processo de desenvolvimento.

Todos esses elementos, que compõem os jogos educacionais digitais, contribuem para o desenvolvimento de habilidades e competências, inerentes ao mundo moderno e a Cultura Digital das crianças e seus usuários, na medida em que amplia o arcabouço de linguagens digitais; estimula vivências e ações com o uso das TDIC; promovem a autonomia, a criatividade e o protagonismo dos estudantes, dando ênfase na utilização de ferramentas tecnológicas com intencionalidade educativa; estimulam aulas interativas e audiovisuais que facilitam a internalização do conhecimento.

\section{AGRADECIMENTOS}

Agradecemos à Universidade Franciscana (UFN) pelo apoio na realização do projeto desse jogo.

\section{REFERÊNCIAS}

ALMEIDA, Maria E. B.; PRADO, Maria E. B. B. Um retrato da informática em educação no Brasil. 1999. Disponível em:<http://www.proinfo.gov.br> Acesso em: 22/08/2021

BRASIL. Lei de Diretrizes e Bases da Educação Nacional, LDB. 9394/1996. São Paulo: Saraiva, 1996.

BRASIL. MINISTÉRIO DA EDUCAÇÃO. SECRETARIA DE EDUCAÇÃO BÁSICA. Base Nacional Comum Curricular. Brasília, 2016.

CAON, Â. P.; SANTOS, L. R. A. Possibilidades e limites do ensino em matemática por meio do WhatsApp. In: Anais do Encontro Capixaba de Educação Matemática X, 2015. Espírito Santo. Disponível em: $<$ http://ocs.ifes.edu.br/index.php/ECEM/X_ECEM/paper/viewFile/1899/621> Acesso em: 20 set. 2021.

CSIKSZENTMIHALYI, Mihaly. Teoria do Flow, pesquisa e aplicações. Revista ComCiência [on-line]. n.161, 2014. Disponível em: http://comciencia.scielo.br/scielo.php?script=sci arttext\&pid=S151976542014000700010\&lng=en\&nrm=iso24 Acesso em: 27 set.2021. 
DORNELES, T. P.; TORRES, P.; BULEGON, A.M. Jogo digital para o desenvolvimento do Pensamento Lógico-Matemático. Revista Tecnologias na Educação, Ano 11, Vol. 32, Edição Temática XIII - 3ํㅗㅇ Simpósio Internacional sobre Games, Gamification e Tecnologias na Educação, UFSM: Santa Maria/RS, Dez.2019 Disponível em: https://tecedu.pro.br/wp-content/uploads/2020/02/Art3-Ano-11-vol32Dezembro-2019.pdf-.pdf Acesso em 26 set.2021.

HALPERN, D. F. Teaching for critical thinking: Helping college students develop the skills and dispositions of a critical thinker. New Directions for Teaching and Learning, 80, 69-74, 1999.

KLOPFER, E.; OSTERWELL, S. e SALEN, K. Moving learning games forward: obstacle, opportunities e openness. Education Arcade. MIT, 2009. Disponível em: <http://education.mit.edu/papers/MovingLearningGamesForward_EdArca de.pdf\#page=5\&zoom=auto,0,395> Acesso em 20.05.21.

MATTAR, J. Games em educação: como os nativos digitais aprendem. São Paulo: Pearson Prentice Hall, 2010.

PRENSKY, M. Nativos digitais, Imigrantes digitais, 2001. Disponível em: https://colegiongeracao.com.br/novageracao/2 intencoes/nativos.pdf . Acesso em: 15 set. 2021.

SASSAKI, C. Educação 3.0: uma proposta pedagógica para a educação. São Paulo: Geekie. 2017. Disponível em: https://www.geekie.com.br/blog/ebookeducacao-3-0/ Acesso em 15 set.2021. 